NBER WORKING PAPER SERIES

\title{
WHEN INNOVATION GOES WRONG: TECHNOLOGICAL REGRESS AND THE OPIOID EPIDEMIC
}

\author{
David M. Cutler \\ Edward L. Glaeser \\ Working Paper 28873 \\ http://www.nber.org/papers/w28873 \\ NATIONAL BUREAU OF ECONOMIC RESEARCH \\ 1050 Massachusetts Avenue \\ Cambridge, MA 02138 \\ May 2021, Revised October 2021
}

We are grateful to Toby Chaiken, Julia Dennett, and Travis Donahoe for expert research assistance. We are also grateful to Leonard Young and Netrali Dalvi of the Massachusetts Prescription Drug Monitoring Program for providing assistance with MA's Prescription Monitoring Program (PMP) data, Adam Berrones and Dave Hopkins for providing assistance with Kentucky's All Schedule Prescription Electronic Reporting (KASPER) data, and Gilbert Samia for providing assistance with California's Controlled Substance Utilization Review and Evaluation System (CURES) data. This research was supported by the National Institute on Aging of the National Institutes of Health under award number R37AG047312. Cutler is involved in the multi-district litigation regarding opioids as an expert witness to the plaintiff counties suing opioid manufacturers, distributors, and dispensers. Additional detail on the data and results presented are available in the online appendix. The views expressed herein are those of the authors and do not necessarily reflect the views of the National Bureau of Economic Research.

At least one co-author has disclosed additional relationships of potential relevance for this research. Further information is available online at http://www.nber.org/papers/w28873.ack

NBER working papers are circulated for discussion and comment purposes. They have not been peer-reviewed or been subject to the review by the NBER Board of Directors that accompanies official NBER publications.

(C) 2021 by David M. Cutler and Edward L. Glaeser. All rights reserved. Short sections of text, not to exceed two paragraphs, may be quoted without explicit permission provided that full credit, including $\odot$ notice, is given to the source. 
When Innovation Goes Wrong: Technological Regress and the Opioid Epidemic David M. Cutler and Edward L. Glaeser

NBER Working Paper No. 28873

May 2021, Revised October 2021

JEL No. I0,J1

\begin{abstract}
$\underline{\text { ABSTRACT }}$
The fourfold increase in opioid deaths between 2000 and 2017 rivals even the COVID-19 pandemic as a health crisis for America. Why did it happen? Measures of demand for pain relief - physical pain and despair - are high and in many cases rising, but their increase was nowhere near as large as the increase in deaths. The primary shift is in supply, primarily of new forms of allegedly safer narcotics. These new pain relievers flowed in greater volume to areas with more physical pain and mental health impairment, but since their apparent safety was an illusion, opioid deaths followed. By the end of the 2000s, restrictions on legal opioids led to further supply-side innovations which created the burgeoning illegal market that accounts for the bulk of opioid deaths today. Because opioid use is easier to start than end, America's opioid epidemic is likely to persist for some time.
\end{abstract}

David M. Cutler

Department of Economics

Harvard University

1875 Cambridge Street

Cambridge, MA 02138

and NBER

dcutler@ harvard.edu

Edward L. Glaeser

Department of Economics

315A Littauer Center

Harvard University

Cambridge, MA 02138

and NBER

eglaeser@harvard.edu

A data appendix is available at http://www.nber.org/data-appendix/w28873 
The fourfold increase in the death rate from opioid drugs between 2000 and 2017, illustrated in Figure 1, is an American health crisis rivalling even the COVID-19 pandemic. Nearly 500,000 people died from opioid overdoses between 1999 and 2019, and in 2019, more people died from opioids $(70,630)$ than from motor vehicle accidents $(38,800)$ or breast cancer $(42,281)$ (Centers for Disease Control and Prevention, National Center for Health Statistics 1999-2019). The increase in drug overdose deaths is a major reason for recent declines in US life expectancy (Kochanek, Arias, and Bastian 2016; Woolf and Schoomaker 2019) and has contributed to the longer-term stagnation of life expectancy first emphasized by Case and Deaton (2015). The opioid crisis has also exacerbated the link between lifespan and education; opioid death rates are far higher for those without a Bachelor of Arts than for those with one (Ho, 2017). Opioid deaths rose during the COVID pandemic, despite the sharp reductions in mobility (Goodnough, 2021).

At its heart, the opioid story is one of technological regress. It was hoped that opioids would end America's longstanding scourge of untreated pain, just as antihypertensives, cholesterollowering agents, and antidepressants brought therapy to millions of previously untreated people with high blood pressure, high cholesterol, and mental illness. It was not to be.

The opioid epidemic began with the availability of OxyContin in 1996. OxyContin was portrayed as a revolutionary wonder drug: because the painkiller was released only slowly into the body, relief would last longer and the potential for addiction would decline. From 1996 to 2011, legal opioid shipments rose six-fold. But the hoped-for benefits proved a mirage. Pain came back sooner and stronger than expected. Tolerance built up, which led to more and higher doses. Opioid use led to opioid abuse, and some took to crushing the pills and ingesting the medication all at once. A significant black market for opioids was born. 
Fifteen years after the opioid era began, restrictions on their use began to bind. From 2011 on, opioid prescriptions fell by one third. Unfortunately, addiction is easier to start than stop. With reduced access to legal opioids, people turned to illegal ones, first heroin and then fentanyl, which has played a dominant role in the recent spike in opioid deaths.

In this essay, we begin with a brief sketch of the history of opioids and the rise of their use in the United States since about 1995. Our main focus is on the positive question of how demand for and supply of opioids produced the epidemic. In considering demand, we look at available measures of physical and mental pain, despair, and the opportunity cost of time, which is associated with joblessness and social isolation. We show that changes in demand-side factors alone, such as physical pain, depression, despair, and social isolation can only explain a small fraction of the increase in opioid use and deaths from 1996 to 2012. However, we also find that patterns of demand helped to shape the locations in which the opioid crisis became most severe.

The dominant changes in opioid supply started with modest technological and marketing innovations in the legal sector, which was followed by a burst of entrepreneurship in the illegal sector. In the legal market, physicians who cared about treating the impaired were persuaded by a time release system and a highly effective-marketing campaign that the new opioids were truly safer than the older ones, and they started prescribing. While the opioid crisis did not begin with supply shifts in the illegal market, technological and institutional changes within that market furthered the epidemic. The introduction of fentanyl and the rise of Asian fentanyl exports appears to be a narcotic variant of the China trade shock, where declining transport costs and East Asian industrial expertise flooded American markets and displaced the opium producers of Mexico (Grandmaison, Morris, and Smith 2019).

Opioid prescriptions are now down substantially from their peak. However, even if the 
reduction in legal opioid prescriptions since about 2011 reduces the flow of new addicts, the stock of existing addicts will continue to seek supply, even when it means substituting into more dangerous illegal sources. Thus, the opioid epidemic is likely to be with us for some time to come.

\section{The Opioid Crisis and its History}

Opiates are naturally occurring substances that can be extracted from the opium poppy plant. The plant can be smoked directly, or purified into more potent opiates including legal drugs like codeine and morphine, or illegal drugs like heroin. The term opioid refers also to semisynthetic drugs such as oxycodone (the key ingredient in OxyContin), hydrocodone, and hydromorphone, and to fully synthetic drugs such as fentanyl and methadone.

The various derivatives of opium are chemically similar, but their potency varies greatly (CMS 2017). Codeine has 15 percent the potency of morphine, while oxycodone has 150 percent of morphine's potency. Heroin is roughly three times as potent as morphine, and fentanyl is 100 to 200 times more potent than morphine, with the variation arising because the potency of illegal drugs varies from batch to batch.

Opioids relieve pain and make people feel calm and happy. They also depress basic bodily functions such as respiration and cardiac activity. For this reason, a dose that is far enough above the typical amount can lead to death, even among tolerant users. Unfortunately, the line between euphoria and death is not very wide by therapeutic standards. Gable (2004) finds that for intravenous heroin, the lethal dose is only six times the effective dose, making it the most dangerous of common drugs. 


\section{The Ultimate Addictive Good}

Opium has been used to stimulate pleasure and relieve pain since at least 3400 BCE. There are Sumerian references to the “joy plant” (Booth 1996; Saunders 2014). Opium was well-known to civilizations from Greece to Egypt to Persia to India, both for its beneficial effect and possible overdoses. Hippocrates (460-377 BCE), the father of modern medicine - from whom we have the Hippocratic Oath - frequently mentioned the poppy in his remedies. Herakleides of Pontus ( 340 BCE) in his book On Government describes how one island's inhabitants regularly committed suicide "by means of the poppy” (Saunders 2014). Avicenna's $11^{\text {th }}$ century Canon of Medicine warned that "the most powerful of the stupefacients is opium," which made it a useful painkiller, but that it was also "definitely poisonous.”

Opium became a major trade good and a source of conflict during the Age of Exploration. Britain and China fought two Opium wars, which ended with the British protecting their right to sell opium in China. Perhaps one in five Chinese men were opium users early in the $20^{\text {th }}$ century (United Nations Office on Drugs and Crime 2010), and the Chinese opium epidemic only ended when the Communists imposed draconian restrictions on consumption.

Opium's combination of danger and pleasure has led to repeated cycles of innovation, addiction and rection, which begin when entrepreneurs produce an allegedly safer opioid. However, when purchasers begin consuming the new drug, they discover that this new innovation is as addictive and deadly as the old forms of opium. New consumers avoid the drug or are prohibited from using it. Existing users pass away, and the fad dies down - until memories fade and the cycle begins again. London physician Thomas Sydenham combined opium with alcohol in 1676 to produce laudanum, a wonder drug that eliminated almost all forms of pain-and which became its own substance abuse problem. Twenty-five years later, in 1701, Dr. John Jones wrote 
in "The Mysteries of Opium Reveal'd" that long term use of opium generates an "inability or listlessness to do any things except it be while the Opium operates," but that quitting opium use could leave to "intolerable ... anxieties," and even a "miserable death."

In 1804, Friedrich Serturner separated “morphine” from opium. He believed that he had discovered a safe medication, but he would himself become an addict. Several decades later, Merck pioneered the drug commercially. Morphine and opium were widely used as painkillers during the US Civil War, and morphine addiction was termed the "Soldier's Disease" in the last third of the $19^{\text {th }}$ Century.

By 1872, the Annual Report of the State Board of Health of Massachusetts noted that "the sulphate of morphia seems to be growing in favor," and that "this salt is not only taken internally, but is sometimes used hypodermically." The Report repeats the canard that morphine is "free from the more objectionable properties of opium," but also reports (p. 167) a comment from a state assayer that "among the most dangerous preparations of morphia are those now prescribed and sold by uneducated or villainous individuals as so-called 'cures' for persons afflicted with the uncontrollable appetite for opium.”

Pierre Robiquet isolated codeine in 1832, and it remains the most commonly prescribed opiate today. Felix Hoffmann at Bayer was trying to produce codeine when he stumbled upon heroin, a more potent form of morphine. Bayer's marketed heroin, claiming: "Heroin is completely devoid of the unpleasant and toxic effects of opium derivatives.” The Boston Medical and Surgical Journal (the forerunner of the New England Journal of Medicine) informed its readers in 1900 that heroin "possesses many advantages over morphine as a respiratory sedative," especially an “absence of danger of acquiring the habit” (February 20, 1900, v. 142, p. 190). Heroin was sold to suppress coughs, relieve the burden of childbirth and war injuries, prepare for anesthesia, and 
control certain mental disorders. As the dangers of heroin became clear, Bayer phased out its promotion in favor of another new compound, acetylsalicylic acid (aka aspirin), also synthesized by Felix Hoffmann.

Semi-synthetic and synthetic opioids were developed in the $20^{\text {th }}$ century. In 1916 , two German scientists produced oxycodone, and it became a popular painkiller for the Nazis; Hitler and Goering both appear to have been enthusiasts (Ohler, 2017). Fully synthetic opioids came later still. Fentanyl was created in Belgium in 1959, and Tramadol was developed in Germany in 1962.

Opioids are an extreme example of the addictive goods analyzed by Becker and Murphy (1988). They have strong intertemporal complementarity in consumption: past use greatly increases the marginal benefit of current use. Further, there is a large tradeoff between short-term mood advantages and longer-term downsides. The longer-term costs from opioids are not direct health costs like the lung damage generated by cigarettes on smokers but are indirect and mediated by addiction or “tolerance.” When addicts attempt to satisfy their habit, especially by using illegal opioids, they pay financial costs and face risk of overdose and death. Nutt et al. (2007) surveyed experts to determine a scale of harm for 20 different drugs and found that heroin generated the highest level of dependence and risk of an overdose. ${ }^{1}$

\section{The Illegal Supply of Opioids before the Epidemic}

US legislation in the early $20^{\text {th }}$ century sought to limit opioid use as a way to reduce widespread morphine and heroin abuse. The Harrison Narcotics Tax Act of 1914 required consumers to have a doctor's prescription to gain access to opiates, and doctors were typically

\footnotetext{
${ }^{1}$ Of the world's most widely used drugs, only caffeine appears to have practically no well-documented long-term health costs.
} 
skeptical about prescribing drugs that appeared to be addictive. After 1917, the Act was interpreted to mean that doctors should not prescribe opiates to addicts merely to maintain their habits. Heroin was banned in 1924, owing to its alleged impact on crime. Codeine remained a mainstay of cough suppressants, but medical prescriptions of other opiates plummeted.

Legal restrictions did not end the supply of opioids; rather, that supply moved underground.

Before World War II, at least in Chicago, opium smoking was far more common than heroin injection and it was concentrated in the city’s Chinatown (Dai 1937). Between the 1950s and 1972, America's heroin supply appears to have been primarily produced from poppies grown in Turkey and smuggled in through the "French Connection.” That route was disrupted by law enforcement in 1972, and the price of heroin correspondingly rose (Brown and Silverman, 1974). The combination of high prices and the shutdown of the European supply chain attracted other entrepreneurs, from Southeast Asia’s Golden Triangle to Afghanistan’s Golden Crescent, and later Mexico.

The long-run supply of heroin seems to be quite elastic. Heroin prices fell over 80 percent in real terms between 1981 to 2001. However, the new supply sources boosted consumption, and heroin-related deaths started rising again in the early 1990s (as shown in Figure 1). Still, none of these heroin crises saw death rates anywhere near those that appeared after 2010.

\section{The Rise of Opioid Use}

Trends in legal opioid use in the past two decades are shown in Figure 2, which presents aggregate shipments of opioids per adult - in milligrams of morphine equivalents, or MMEs from 1997 through 2017. The data underlying figure 2, and all data on legal opioid shipments that 
we present, are from the Drug Enforcement Administration's Automation of Reports and Consolidated Order System (ARCOS), which details shipments by product and three-digit zip code. We aggregate the ARCOS data to counties or the nation as appropriate. The appendix has more detail. Fifty MME is a typical daily dose for a person in pain. Thus, total opioid supply in 1997 was roughly three days of typical use per adult. By 2011, the supply was 20 days per person - roughly one prescription per adult per year. The overall growth was 461 percent. OxyContin was a major part of the total. Oxycodone shipments rose 27 percent annually from 1997 to 2011. Shipments of other opioids rose as well, though none to quite the same extent.

The increased use of opioids involved changes on the extensive and intensive margin (see the Appendix for details). Our primary source of prescription data is the Medical Expenditure Panel Study (MEPS), an ongoing survey of the non-institutional population since 1996. MEPS data show that opioid prescriptions per capita doubled between 1996 and 2010. Data from IMS Health show similar trends. One-quarter of the increase in prescriptions came from the extensive margin of more people being prescribed medications; three quarters was due to the intensive margin of more scripts per person. In addition to more prescriptions, data from the Massachusetts Prescription Drug Monitoring Program (PDMP) show that days supplied per prescription increased by a quarter from 2000 to 2012.

The increase in the number of people receiving prescriptions, the number of prescriptions per recipient, and the number of pills per script does not add to the total increase in opioid shipments. It is possible that the gap is due to high volume 'pill mills', not all of which might be recorded in national survey data.

The appendix shows variability in opioid use along several dimensions, using the MEPS data. We focus on the share of people with two or more prescriptions in the $\sim 2 \frac{1}{2}$ years people are 
asked about in the survey, to capture heavy use. There are stark differences in heavy use by education. In 2009, 13 percent of people without a college degree had more than one opioid script, compared to 9 percent of people with a college degree. Opioid use also began to fall earlier for people with college degrees. In 1998, opioid use was the same in rural and urban areas, but then it rose more rapidly in rural areas. By 2012, 15 percent of rural residents had more than one opioid scipt, as opposed to 10 percent of ubanites. Heavy use declined more rapidly in urban areas after 2012, further increasing the gap between country and city. Differences by labor force participation are also marked: 20 percent of people aged 25-44 who were out of the labor force were heavy opioid users in 2012, compared to 10 percent for blue collar workers and 6 percent for white-collar workers.

The MEPS also allows us to see whether opioids served as a substitute for other medications. To examine this, we take advantage of the panel nature of the data. People are in MEPS for 5 rounds, each lasting about half a year. Starting with the 2001 panel, people in the second round were asked: "During the PAST 4 WEEKS, how much did PAIN interfere with your normal work (including both work outside the home and housework)?” We count people as in pain if they answer "moderately," "quite a bit," or "extremely," as opposed to "not at all” or "a little bit.”

We sample people who are in pain in the second round of the survey, but who were not taking opioids, antidepressants, or anxiolytics in the first round. Among that group, the share of opioid user increased dramatically from about 6 percent in 2001 to about 9 percent in 2009 (see the appendix). The use of antidepressants and anxiolytics (anti-anxiety medications) was generally flat. Use of other pain medications, for example high dose prescription non-steroidal anti- 
inflammatories, fell. Thus, is appears that opioids primarily substituted for less powerful pain relievers but not for antidepressants or anti-anxiety medications.

\section{Shifting Demand and the Rise of Opioids}

Opioid use is determined by the interaction of demand and supply in the linked markets for legal and illegal drugs. The observed increase in opioid use can reflect an increase in demand, in supply, or both. Demand factors can explain the course of the opioid epidemic either because rising opioid use reflect shifts in demand, or because rising supply drives up national opioid use, but local demand factors determine where that supply has the most impact. Here we address whether demand shifts on their own can explain the national rise in opioid use. We consider four potential demand shifters for opioids: physical pain; depression; despair; and social isolation.

Demand-Side Forces: Physical Pain, Depression, Despair, and Opportunity Cost of Time

Jeremy Bentham (1789, p. i) famously noted: "Nature has placed mankind under the governance of two sovereign masters, pain and pleasure." Opioid use replaces pain with pleasure. As pain increases, one would naturally expect opioid use to increase as well, as happened after the Civil War.

Opioid use might also appeal to individuals who are in psychic pain: Case and Deaton (2017) famously termed America's rising middle-aged mortality rates "deaths of despair." However, pain associated with physical and mental impairment differ in a central way. Physical pain, suffered on the factory floor or the battlefield, may be unrelated to any other personal attribute. Mental pain, generated by disorders such as depression or a consequence of social and 
economic changes, often co-exists with other characteristics that may either increase or decrease the demand for opioids. Anxiety, for example, might reduce opioid use by generating increased fear of addiction or an inability to take actions, like finding a cooperative doctor or dealer.

Opioids may relieve pain and lessen despair, but for most consumers, use comes at a cost of diminished attention and energy. Serious opioid consumption produces lethargy and diminishes interest in other people. Consequently, the demand for opioids should be higher among people with a lower opportunity cost of time. An extreme version of this hypothesis is that opioids can be a complement to doing nothing, because the short-term pleasure generated by opioids is large and independent of most other activities. For much of the past decade, more than 15 percent of 25-54 year-old men have not been employed. The employment to population ratio for these "prime-aged" men has been less than 75 percent in many parts of America's eastern heartland, where opioid use has been severe (Austin, Glaeser and Summers, 2018). Krueger (2017) reports that one-half of jobless men take some form of painkillers.

\section{Patterns of Demand-Side Variables}

Figure 3 shows national-level trends in four variables related to these explanations: physical pain; depression; despair; and social isolation. Trends in these variables are age- and sexadjusted to the 2000 US population when possible. Panel a shows two measures of pain in the MEPS. The first is the measure of pain interfering with work in the past four weeks, noted above. The second is whether the person reports one of 11 painful conditions, for example arthritis or back pain. Pain in the US is high. About 20 percent of people report that pain interfered with their normal work at least moderately in the past four weeks and 25 percent report a painful condition. The share of people reporting that pain interfered with their work is relatively constant, but the 
prevalence of reporting at least one painful condition increased 14 percent. The difference between these two may imply that pain treatment is somewhat effective, or it could be that pain is now given a diagnosis where formerly it was not. Panels b, c, and d report the share of adults visiting the emergency department for any injury or a workplace injury; the share of adults with joint pain, back pain, or neck pain; and the share of adults with neck, facial, or sciatic pain, the latter two taken from the National Health Interview Survey. As in MEPS, about one-third report musculoskeletal pain, and this increased about 12 percent over the time period. Neck, facial, or sciatic pain rose about 5 percent. Emergency room visits for injuries declined.

Panel e shows mental health impairment, the share of people with poor mental health all or most days from the Behavioral Risk Factor Surveillance System Annual Survey. Trends are split in 2011, where there was a change to BRFSS weighting methodology, and as is described in the Online Appendix. ${ }^{2}$ Each has increased over time, by 41 percent and 85 percent respectively. Panel f shows a measure of despair, average life satisfaction (Gallup 1997-2015). The survey shows that 86 percent of people were satisfied with their life in 1996 and 2019; the share has remained between 73 and 87 percent since 1979. Life satisfaction rebounded after the Great Recession.

The last two panels (g and $\mathrm{h}$ ) capture social isolation and the opportunity cost of time: the share of the 25-54 year-old male population that is not employed and the share of the population aged 25-64 that is never married. Both of these measures have increased, the latter especially so. The percent of 18-34 year-olds who are married fell from 58 percent in 1978 to 29 percent in 2018. The share of Americans who live alone increased from 13 percent in 1960 to 28 percent in 2016. Putnam (1994) documents the widespread decline of many different forms of social connection,

\footnotetext{
${ }^{2}$ See "Can the 2010 BRFSS dataset be compared with 2011 dataset?" https://www.cdc.gov/surveillancepractice/reports/brfss/brfss_faqs.html
} 
from bowling leagues to fraternal clubs. Quinones (2015) explicitly links the rise of opioid abuse to weakening social ties, particularly in the eastern heartland.

\section{Demand and Opioid Initiation}

As shown in Figure 3, many of the measures of pain and despair increase in prevalence over time, but they do not increase enough to offer a promising source of explanation for the fourfold increase in opioid deaths or the six-fold increase in opioid shipments from 1996 to 2012. Figure 4 shows this informally, focusing on the 2001-02 and 2009-10 cohorts. The first cohort is the earliest with good pain data; the latter is at the height of opioid prescribing.

The figure shows that the share of people with $2+$ painful conditions rises slightly across the two time periods, but the share of people with 2+ conditions who have at least 2 opioids scripts in the $2 \frac{1}{2}$ years they are in the MEPS rises by even more. The lion's share of the growth in opioid use comes from increased number of prescriptions, holding the number of pain categories fixed, not from the increase in the number of people reporting multiple forms of pain.

The appendix shows the role of demand-side factors in the growth of opioid utilization more formally. We sample people in the MEPS who are opioid-naïve in the second round. For this group, we record several measures of potential demand for opioids: whether the person reports pain, based on the two measures above; how much of the past four weeks the person felt downhearted and depressed, which we scale from zero to one; and several measures of social isolation, including labor force participation and marital status. We relate each of these variables to the onset of heavy use opioids (2 or more opioid prescriptions) after the second round.

All of these variables are associated with subsequent use of opioids. Controlling for basic demographics, health care access, and other health behaviors, an individual in extreme pain has a 
15 percentage point higher probability of initiating multiple opioid prescriptions than an individual with no pain, a person who reported being downhearted and depressed all of the time in the past four weeks is 5 percentage points more likely to initiate heavy opioid use than one reporting no time spent downhearted and depressed, and a person who is widowed, separated, or divorced is 2 percentage points more likely to initiate heavy opioid use than a married person. However, most of these variables did not increase enough over time to explain the growth in opioid use. Regressions including the report of painful conditions explain 20 percent of the growth in heavy opioid use; regressions using pain interfering with work explain only 4 percent of that increase. The same pattern appears when looking at explaining the growth in the use of any opioid.

As MEPS does not have a good measure of despair, we turn to the Midlife in the US Survey (MIDUS) to examine the impact of despair on opioid use. MIDUS is a panel of roughly 7,000 people who were interviewed in 1995-97, in 2004-05, and a third time in 2013-15. We consider whether an opioid-naïve person in one survey round (i.e., round 1 or 2) becomes a user of prescription pain relievers by the next round, controlling for basic demographics. MIDUS asks about prescription pain relievers in general, not opioids in particular. The bulk of prescription pain relievers, but not all, are likely to be opioids. On average, 27 percent of people in waves 2 and 3 take prescription pain relievers.

MIDUS asks a number of questions on health and outlook. We combine groups of questions into summary statistics meant to capture the categories of pain, negative affect, despair, economic insecurity, and social isolation (see the appendix). Measures that feed into despair include life satisfaction, social integration, and perceived contributions to society. Economic insecurity includes measures of their financial situation and difficulty paying bills. 
The MIDUS results for pain and negative affect are similar to those in the MEPS. People in pain are more likely to initiate prescription pain relievers, as are people with negative affect; the impact of pain is quantitatively larger. Despair and economic insecurity matter for opioid initiation as well. A one standard deviation increase in despair increases the probability of subsequent prescription pain reliever use by 3 percentage points; a one standard deviation increase in economic insecurity leads to a 6 percentage point increase in prescription pain reliever initiation. Taken as a whole, however, changes in pain, negative affect, despair, and economic insecurity predict only one-quarter of the increase in prescription pain reliever use. In the Online Appendix, we report trends in a wider variety of health, pain, and despair metrics from MEPS, NHIS, and BRFSS. As has been shown by Case and Deaton (2020) and others (Blanchflower and Oswald 2020; Case, Deaton, and Stone, 2021; Nahin, et al., 2019; IOM, 2011), many metrics for pain and some metrics of mental health impairment and despair have worsened over time, although others have improved. The increases are larger for people without a college degree. However, even changes in the metrics with the largest adverse growth in the past two decades, where increases have been roughly 20-50 percent, pale in comparison to the rise in opioid deaths.

\section{Other studies}

A number of studies have examined the effect of economic change on opioid use and abuse (see Maclean et al., 2020, for a review). The general finding confirms the results above: economic change over the past few decades is related to opioid overdose deaths, but the impact of economic changes on the rise in overall opioid use is modest. For example, Pierce and Schott (2020) estimate that an increase from the $25^{\text {th }}$ to $75^{\text {th }}$ percentile in a county's import competition from China (due to the permanent normal trade relations bill in 2000) was associated with between 2 and 3 
additional drug overdose deaths per 100,000 people, less than 20 percent of the increase in the drug overdose death rate between 1999 and 2018. Similarly, Ruhm (2019) and Case and Deaton (2017) estimate that medium term economic changes such as unemployment rates and median income, have only a minor effect on opioid deaths. Ruhm (2018) estimates that from 1999 to 2015, changes in unemployment, poverty, median household incomes, home prices, and exposure to import competition — taken together-explain fewer than 10 percent of the increase in opioid deaths.

One paper reaching a different conclusion is Charles et al. (2019). That paper uses statelevel data to estimate that the decline in manufacturing share of employment between 2000 and 2015 could explain virtually all of the increase in opioid deaths over that time period. In the appendix, we explore this relationship in more detail (we are grateful to Charles et al. for providing us their data and replication code). Because the data are at the state level, Charles et al. do not include other controls in their regression. Estimating the model at the commuting zone level and including basic demographic controls such as population age shares and median income eliminates the relationship between manufacturing decline and opioid deaths. We thus conclude that the direct effect of economic change on opioid deaths is modest. Changes in supply seems to be far more like causes of the opioid epidemic than changes in demand-side factors including pain and despair.

\section{The Changing Supply of Opioids}

If increases in demand do not explain the increase in opioid use, the obvious alternative explanation is supply. Indeed, the recent opioid cycle is reminiscent of the supply-driven cycles seen for morphine in the $19^{\text {th }}$ century and heroin in the early $20^{\text {th }}$ century. In each of these cases, a 
pharmaceutical company produced a new and supposedly safer version of opium. Consumers bought the new drug, only to learn that it was no less addicting. Demand falls until the stock of addicts decline and memories fade, whereupon the cycle starts anew. The history of Purdue Pharma and OxyContin after 1996 follows a similar pattern, though technology has had an extra impact pushing the current cycle into illegal use.

\section{Creating an Epidemic}

OxyContin was approved by the Food and Drug Administration in December 1995 and Purdue began marketing in earnest in 1996. Three factors enabled Purdue to turn OxyContin into a blockbuster drug. First, Purdue managed to differentiate OxyContin sufficiently from past opioids, both because the semi-synthetic opioid oxycodone had less of a history than did morphine, and through the delayed-release "Contin" system. The time release system, it was hypothesized, would moderate the amount of the opioid received at any point in time, which would reduce the risk of dependence and increase the time between needed doses. ${ }^{3}$ At the time of FDA approval and even after, no clinical trials backed up this theory.

Second, Purdue was a dynamo at drug marketing. Arthur Sackler, the oldest of the three Sackler brothers who owned Purdue, revolutionized pharmaceutical sales. He advocated “detailing, free samples, free food and drink, flashy journal advertising and mailings” (Podolsky et al., 2019, p. 1786). The 2019 lawsuit by the Commonwealth of Massachusetts against Purdue details cases such as a doctor who was visited by Purdue representatives more than 600 times after 2008 and was given a consulting contract to promote Purdue opioids. That doctor allegedly

\footnotetext{
${ }^{3}$ In 1984, Purdue Pharma tried this approach with MS Contin, which delivered morphine slowly into the body. The forthcoming expiration of that patent, combined with the perception by physicians that morphine was too potent to give to patients on a long-term basis, led Purdue to search for other formulations (Sarpatwari, Sinha, and Kesselheim, 2017).
} 
prescribed hundreds of thousands of Purdue opioid pills, generating nearly \$1.5 million of revenue for Purdue.

Third, Purdue's sales pitch rode the wave created by a nascent medical movement focused on the alleviation of pain. In 1973, the anesthesiologist John Bonica convened a meeting of pain specialists and founded the International Association for the Study of Pain, which had its own peer-reviewed journal: Pain. Dame Cicely Saunders, a hospice pioneer, advocated using morphine to alleviate the suffering of dying patients: obviously, in the case of dying patients, potential longrun costs of opioid use are not relevant. Purdue and other makers of pain medications provided financial support for at least one chapter of the International Association for the Study of Pain: the American Pain Society, which shut down in 2019 under a blizzard of lawsuits claiming it was a front company for opioid manufacturers and should be partly liable for the opioid epidemic.

Traditionally, opioid pain relief was considered for patients with end-stage cancer or acute trauma. Addiction was of little consequence for the first group and use for the latter group was generally limited to inpatient care. Thus, the real shift for OxyContin was in the use of opioids for the much larger group of people with chronic pain in outpatient settings.

The key to making this switch was overcoming the fear of physicians that such patients would become addicted to opioids. To win over the doctors, Purdue promoted a 1980 letter to the New England Journal of Medicine claiming that among " 11,882 patients who received at least one narcotic preparation, there were only four cases of reasonably well documented addiction in patients who had no history of addiction” (Porter and Jick, 1980). This finding was among inpatients but was taken to be general.

It is unclear whether doctors believed the advertising or were induced by the promotions. In either case, prescriptions flowed. 
Purdue and other pharmaceutical manufacturers were behaving like stereotypical amoral profit-maximizing companies, but they also met little resistance. A National Academy of Sciences panel (2021) noted several system-wide failures in the opioid epidemic. Pharmaceutical distributors and dispensers both have legal obligations to watch for diversion of products, but they are also profit-maximizing entities who benefitted from the sale of opioids.

Physicians are the ultimate gatekeepers for prescription medicine, and many of them behave far more altruistically than any simple homo economicus. Yet not all doctors are saints, and some wrote very large numbers of opioid prescriptions. Prescription Drug Monitoring Program data show that in 2011, prescribers in the top 5\% of the prescribing distribution wrote 58 percent of total prescriptions in Kentucky, 36 percent in Massachusetts, and 40 percent in California.

Both the Food and Drug Administration and the Drug Enforcement Administration made decisions that enabled the massive increase in opioid prescriptions (Egilman et al., 2019; Kolodny, 2020; Office of the Inspector General, 2019). The FDA generally requires at least two long-term studies of safety and efficacy in a particular condition before drug approval, but for OxyContin, the primary trial for approval was a 2-week trial in patients with osteoarthritis. Even with this limited evidence, the FDA approved OxyContin "for the management of moderate to severe pain where use of an opioid analgesic is appropriate for more than a few days" - with no reference to any particular condition and no limit to short-term use.

In approving subsequent opioids, the FDA sometimes relied on clinical trials where all patients were initially placed on the active opioid (open label). Among those who responded favorably and could tolerate the side effects, some were randomized to continue the therapy and others were switched to a placebo. The idea was that the drug would then be tested in efficacy among those for whom it can be tolerated. However, with this design, withdrawal effects from 
ending opioid use could be interpreted as efficacy of the therapy.

Regulatory capture is the standard explanation for lax oversight. Two examiners involved in OxyContin's FDA approval went on to work for Purdue. When the FDA convened an advisory group in 2002 to examine the harms from OxyContin, eight of the 10 experts had ties to pharmaceutical firms.

The DEA is in charge of monitoring use of opioids - it maintains the ARCOS data - and approving increases in production quotas. The DEA approved an increase in production quotas for oxycodone and other opioids numerous times, even as the scope of the opioid epidemic became clear. The DEA has also been blamed for being slow to set up a suspicious order system and to shut down suspected diversion of pills.

States enacted and expanded their prescription drug monitoring programs (PDMPs) (Meara et al., 2016), but these came some years later than many would have wished. Earlier, states had moved away from monitoring prescriptions, for example through triplicate prescribing forms, and these have been shown to have slowed the growth of opioid use (Alpert et al., 2019). Private insurers as well were also slow to curb the use of opioid medications, for examples through formulary restrictions or prior authorization requirements. In a sense, the case of OxyContin only reinforces the point that nimble, well-incentivized, profit-seeking companies can often find their way around a slow-moving regulatory apparatus.

The first hints that OxyContin and its later competitors were no safer than earlier opioids appeared early. By 2001, users had learned that crushing time-release tablets would provide access to the full dose of oxycodone at once (National Drug Intelligence Center, 2001). Further, the painrelieving properties of OxyContin seemed shorter than its promoters promised, and the subsequent pain was intense (Van Zee 2009). In the appendix, we show that the flood of opioids nationwide 
made no difference to the reduction in pain between rounds two and four of the MEPS, regardless of the level of pain in period 2. As the pain continued, there was demand for more frequent and larger doses of medication.

Opioid-related deaths followed the patterns of rising opioid prescriptions. As shown in Figure 1, prior to 1999, only the total rate of opioid deaths was recorded in national data. After 1999, the drug overdose deaths are delineated by type of drug. The overall death rate from drug overdoses in the United States was below five per 100,000 in 1990, despite the notorious crack epidemic and what was known at the time as "Heroin Chic"-when popular musicians, such as Kurt Cobain, were known for their heroin use. The growth rate of opioid deaths shows a trend break almost immediately after Oxycontin was introduced in 1996.

Throughout the 2000s, increasing attention was paid to the abuse of opioids. The National Drug Intelligence Center (2001) report noted with alarm that "the Pike County, Kentucky, Coroner reported 19 Oxycontin-related deaths during the calendar year 2000.” In July 2001, the New York Times published “The Alchemy of Oxycontin” (Tough, 2001), which noted that "the earliest reported cases of OxyContin abuse were in rural Maine, rust-belt counties in western Pennsylvania and eastern Ohio and the Appalachian areas of Virginia, West Virginia and Kentucky.” Congressional hearings as early as 2001 described increased deaths and pill diversion from OxyContin (US House, 2001).

Policy interventions followed, but with a lag. In 2003, the Food and Drug Administration sent a letter warning Purdue that "your advertisements thus grossly overstate the safety profile of Oxycontin," and that "failure to respond to this letter may result in regulatory action, including seizure or injunction, without further notice.” That same year, the DEA released its OxyContin action plan that called for the "rapid reformulation" of Oxycontin to "reduce the abuse of the 
project, particularly by injection.”

Over time, insurers began to restrict access to opioids through their coverage decisions. State governments set up Prescription Drug Monitoring Programs so that physicians could see how many prescriptions their patients were receiving. Altogether, states added 81 new controlled substance laws between 2006 and 2012 (Meara et al. 2016). State and private lawsuits began to target Purdue Pharmaceuticals and other firms in the opioid business. Finally in August 2010, Purdue reformatted OxyContin to make it less vulnerable to abuse. Prescriptions fell, especially for new patients (Zhu et al. 2019), and abuse of oxycontin declined (ICER, 2017).

\section{Illegal Innovation and Globalization}

Stronger drug monitoring programs and reformulating OxyContin did not end the opioid epidemic; rather, they moved demand into the deadlier illegal market. Cicero and Ellis (2015) found that one-third of opioid users switched to other drugs after the reformulation of OxyContin, and that 70 percent of those who identified an alternative drug specified heroin. The change was greater in those states that had the highest levels of OxyContin misuse prior to 2010 (Alpert et al., 2018). Figure 1 shows no reduction in overall death rates after 2011; rather, the decline in deaths associated with prescription opioids is fully offset by the increase in deaths from heroin. Indeed, Evans, Lieber and Power (2019) estimate no impact of the reformulation on overall mortality.

Soon after 2010, imported heroin from Mexico increased in a way that offset the decline in legal opioids. Quinones (2015) describes an almost corporate system, where buyers call dealers, who then deliver heroin on demand. While US demand for heroin generated both competition on quality and violence in Mexico, the US side of the market remained peaceful and efficient, and heroin overdoses rose dramatically until 2016. Better delivery systems that use cell phones also 
make it easier for consumers to buy heroin without going to dangerous, physical drug markets.

Over time, heroin was replaced by fentanyl, which is more potent still and is fully synthetic - thus does not need the poppy plant. Fentanyl is far less costly to produce and the drug's concentrated strength means that it is particularly easy to ship in tiny but still powerful quantities. The downside is that it is even more deadly. Even transmission through the skin can kill naïve users, depending on the dose. In an accounting sense, fentanyl-related deaths explain almost all of the increase in drug overdose mortality between 2014 and 2017. Indeed, the ability to access an Asian supplier of fentanyl over the internet may be far more revolutionary than the ability to buy consumer goods on Amazon. We now ask how this is related to the initial addiction to prescription opioids.

\section{How the Pill Supply Translated into Deaths}

The opioid epidemic was not uniform spatially, nor was it predominantly an urban phenomenon, unlike crack cocaine in the 1980s (Fryer et al., 2013). Figure 5 shows commutingzone level maps of opioid deaths in 1999-01, 2008-10, and 2016-18. Up through 2010, death rates rose the most and were highest in Appalachia, the industrial Midwest (Quinones's book chronicled Southern Ohio), and rural areas of Maine and Nevada. More recently, deaths have increased more in urban areas, as illegal drug markets are more extensive there.

The change in death rates from 2009-2017 was more disparate. Generally, areas east of the Mississippi River have higher deaths due to illegal opioids than areas west of the Mississippi River, perhaps related to the type of heroin available prior to the opioid epidemic (Pardo et al., 2019). Fentanyl mixes better with powdered heroin than black tar heroin, and powdered heroin is more 
common east of the Mississippi. Overall, the cross-area correlation coefficient between opioidrelated mortality rates in 2008-10 and 2016-18 is .45.

To understand the factors explaining these area trends, we examine whether the national shift in legal opioid supply had a larger impact on opioid shipments and deaths in communities with more pain. We consider this alongside the alternative hypothesis that opioid use was driven by despair. The data on opioid shipments are from the ARCOS database. Opioid deaths in each county in each year from 1999-2018 were obtained through a special request of the Centers for Disease Control and Prevention.

The first column of table 1 relates opioid shipments in a county to a first measure of pain, the share of people in a county's labor force receiving Social Security Disability Insurance (SSDI) in 1990, before the opioid epidemic. The pain variable is interacted with national opioid shipments; thus, the coefficient indicates how national drug supply translated into pill availability in areas with more and less preexisting pain. The regressions also control for county and year fixed effects. To focus on legal opioids in the largely unrelated time period, the regressions are for the period 1997-2010. Pain is a potent predictor of opioid shipments. An area with one standard deviation more people on SSDI received 23 percent more opioids than the average area.

Column 2 considers an alternate measure of pain, the share of the population in the 20022005 \& 2007 Behavioral Risk Factor Surveillance Survey (BRFSS) that reports joint pain. This measure is available for 331 large counties. The coefficient is similar to that for SSDI receipt; an area with one standard deviation more pain received 18 percent more opioids.

The third column interacts national opioid availability with the share of people in the county who were dissatisfied or very dissatisfied with life, also drawn from the 2005-2010 BRFSS. Opioid supply did not rise more in areas where more people were more dissatisfied. The fourth 
column interacts opioid availability with a different metric for despair, the percent of people reporting poor mental health in all 30 days during the past month. This variable is also drawn from BRFSS, and we averaged over 2002-2010. Opioid supply increased by 38 percent more in areas with one standard deviation more people reporting this extreme form of mental distress. The fifth column includes all three variables together; among them, the share of people experiencing consistently poor mental health is most related to opioid supply. In the Appendix, we impute joint pain and life dissatisfaction to all counties, using a LASSO regression in the counties where the data are available. We then relate opioid shipments to predicted pain and despair. The results are similar to what we report.

Column 6 translates these shipments into deaths. The regression mirrors that in column 5 , with the exception that the dependent variable is the prescription opioid mortality rate. The sample is again 1997-2010. The coefficients are similar to those in column 4. Receipt of disability insurance, joint pain and extremely poor mental health interact with national opioid supply in leading to prescription opioid deaths; area life dissatisfaction does not interact in this way.

To examine how these factors explain deaths due to illegal opioids, column 6 relates the county's death rate from illegal opioids to the national death rate from illegal opioids interacted with the same county characteristics. We also allow for an interaction between deaths from illegal opioids nationally and per capita oxycodone shipments in 2008, to examine whether greater prescription opioid use translated into more deaths due to illegal opioids (Evans et al., 2019, and Alpert et al., 2018).

Deaths from illegal opioids were greater in areas where pain was greater and where OxyContin shipments were more prevalent. In contrast, despair is not related to deaths from illegal opioids. Overall, therefore, the opioid epidemic was worse in areas where there was more pre- 
existing pain, poor mental health, and where opioid shipments were greater.

Pain is correlated with education at the individual and area level. In the 331 counties with data on pain, the correlation between pain and share with a college degree is -0.11 . Pain is also higher in rural areas, areas with more manual labor, and areas with higher rates of obesity. This in part explains why opioid death rates are higher in areas with historical manufacturing employment and areas with obesity-related health problems.

\section{Conclusion}

America’s battle with opioids is not over. A movement to aid a population suffering from chronic pain has become a national crisis, with pain, despair, and entrepreneurship mixed in an unholy brew. The government may assert its authority over legal opioids, but it seems unable to stem most of the current illegal market supply, which increasingly comes in small shipments from Asia or Mexico. Even a pandemic could not slow the deaths from opioid drugs.

In the past, opioid crises ended slowly. Users painfully detoxified when supplies could not be obtained or died after one too many overdoses. New users were deterred by fear of addiction and physicians' reluctance to prescribe. The current crisis may follow the same slow and painful path, but that is not entirely clear. New technologies have made it much harder to restrict access to illegal opioids. When the poppy plant had to be grown, supply could be curtailed by eliminating poppy fields. In contrast, fentanyl is much easier to produce, and its sale is much harder to stop.

On the other hand, society also has more tools to address addiction - medication-assisted treatment, widespread availability of overdose reversal medication (Narcan), and strong penalties for illegal suppliers - and the use of these treatments is spreading. 
Past US public health efforts offer both hope and despair. Nicotine is an extremely addictive substance and yet smoking rates have fallen dramatically over the past five decades, because of both regulation and fear of death. On the other side, the harms of obesity are also wellknown and average weights are still increasing. We cannot predict whether opioid addiction will decline like cigarette smoking or persist like obesity.

The medical use of opioids to treat pain will always involve costs and benefits, and the optimal level of opioid prescription is unlikely to be zero. The mistake that doctors and prescribers made in recent decades was to assume overoptimistically that a time release system would render opioids non-addictive. Thousands of years of experience with the fruits of the poppy should have taught that opioids have never been safe and probably never will be.

The larger message of the opioid epidemic is that technological innovation can go badly wrong when consumers and regulators underestimate the downsides of new innovations and firms take advantage of this error. Typically, consumers can experiment with a new product and reject the duds, but with addiction, experimentation can have permanent consequences. 


\section{References}

Alpert, Abby, David Powell, and Rosalie Liccardo Pacula. "Supply-Side Drug Policy in the Presence of Substitutes: Evidence from the Introduction of Abuse-Deterrent Opioids,” American Economic Journal: Economic Policy, 2018, 10 (4): 1-35.

Alpert, Abby E., William N. Evans, Ethan MJ. Lieber, and David Powell, “Origins of the opioid crisis and its enduring impacts,” National Bureau of Economic Research Working Paper 26500.

Austin, Ben, Edward Glaeser, and Lawrence Summers, “Jobs for the Heartland: Place-Based Policies in 21st-Century America,” Brookings Papers on Economic Activity, 2018(1), 151255.

Avicenna, The Canon of Medicine, Translated into English by Hameed HA. S. Waris Nawab, Senior Press Superintendent, Jamia Hamdard Printing Press, New Delhi, 1998.

https://www.fda.gov/drugs/information-drug-class/timeline-selected-fda-activities-and$\underline{\text { significant-events-addressing-opioid-misuse-and-abuse }}$

Becker, Gary, and Kevin Murphy, “A Theory of Rational Addiction,” Journal of Political Economy, 1988,_96(4): pp. 675-700.

Bentham, Jeremy, Introduction to the Principles and Morals of Legislation, London: Printed for T. Payne and Son, at the Mews Gate, 1789.

Booth, Martin, Opium: A History, London: Simon and Schuster, 1996.

Centers for Medicare and Medicaid Services, “Opioid Oral Morphine Milligram Equivalent (MME) Conversion Factors,” 2017.

Charles, Kerwin Kofi, Erik Hurst, and Mariel Schwartz, “The Transformation of Manufacturing and the Decline in U.S. Employment,” in Martin Eichenbaum and Jonathan A. Parker, eds., 
NBER Macroeconomics Annual 2018, Volume 33, Chicago: University of Chicago Press, 2019.

Cicero Theodore J., and Matthew S. Ellis, “Abuse-Deterrent Formulations and the Prescription Opioid Abuse Epidemic in the United States: Lessons Learned From OxyContin,” JAMA Psychiatry. 2015; 72(5):424-430.

Cutler, David, M., and Edward Glaeser, "What Explains Differences in Smoking, Drinking, and Other Health-Related Behaviors?” American Economic Review, 2005, 95(2): 238-242.

DeShazo, Richard D., McKenzie Johnson, Ike Eriator, et al., "Backstories on the US Opioid Epidemic. Good Intentions Gone Bad, an Industry Gone Rogue, and Watch Dogs Gone to Sleep,” The American Journal of Medicine, 2018, 131(6): 595-601.

Drug Enforcement Administration, Office of Diversion, Oxycontin Diversion and Abuse, October 2003.

Egilman, David S. Gregory B. Collins, Julie Falender, Naomim Shembo, Ciara Keegan, and Sunil Tohan, “The marketing of OxyContin: A cautionary tale.” Indian Journal of Medical Ethics, Jul-Sep 2019, 4(3), NS:183-93.

Evans, William N. Ethan M J Lieber, and Patrick Power, “How the Reformulation of OxyContin Ignited the Heroin Epidemic," The Review of Economics and Statistics, 2019, 101(1):1-15.

FDA Warning Letter to Purdue, January 17, 2003. Available at http://www.fda.gov/ICECI/EnforcementActions/WarningLetters/2003/ucm147275.htm.

Fingerhut, Lois A., and Christine C. Cox, (1998). Poisoning mortality, 1985-1995. Public Health Reports, 113(3), 218.

Fryer, Roland G., Paul S. Heaton, Steven D. Levitt, and Kevin M. Murphy, "Measuring Crack Cocaine and Its Impact,” Economic Inquiry. 2013; 51(3):1651-1681. 
Gable, Robert S. "Comparison of acute lethal toxicity of commonly abused psychoactive substances,” Addiction 2004, 99, 686-696.

Goodnough, Abby, “Overdose Deaths Have Surged During the Pandemic, C.D.C. Data Shows,” New York Times, April 14, 2021.

Grandmaison, Romain LeCour, Nathaniel Morris, and Benjamin T. Smith, “The US Fentanyl Boom and the Mexican Opium Crisis: Finding Opportunities amidst Violence?”, mimeo, 2019.

Hedegaard, Holly, Arialdi M. Miniño, and Margaret Warner. Drug overdose deaths in the United States, 1999-2017. NCHS Data Brief, no 329. Hyattsville, MD: National Center for Health Statistics. 2018.

Ho Jessica Y., “The Contribution of Drug Overdose to Educational Gradients in Life Expectancy in the United States, 1992-2011.” Demography. 2017;54(3):1175-1202.

Hoyert, Donna L., Elizabeth Arias, Betty L. Smith, Sherry L. Murphy, and Kenneth D. Kochanek, Deaths: final data for 1999. National vital statistics reports. vol. 49. No. 8. Hyattsville, MD: National Center for Health Statistics, 2001..

Institute for Clinical and Economic Review, Abuse-Deterrent Formulations of Opioids: Effectiveness and Value, Final Evidence Report, August 8, 2017.

Jones, John, The Mystery of Opium Reveal'd, London: Printed for Richard Smith at the Angel and Bible without Temple-Bar, 1701.

Joranson, David E., Karen M. Ryan, Aaron M. Gilson, and June L. Dahl, “Trends in medical use and abuse of opioid analgesics,” JAMA 283, no. 13 (2000): 1710-1714.

Kolodny, Andrew, “How FDA Failures Contributed to the Opioid Crisis,” AMA Journal of Ethics, 2020; 22(8): E743-750. 
Krueger, Alan B., "Where have all the workers gone? An inquiry into the decline of the U.S. labor force participation rate,” Brookings Papers on Economic Activity, 2017(2), 1-87.

Maclean, Johanna Catherine, Justine Mallatt, Christopher J. Ruhm, and Kosali Simon, “Economic Studies on the Opioid Crisis: A Review,” NBER Working Paper No. 28067, 2020.

Meara, Ellen, Jill R. Horwitz, Wilson Powell, Lynn McClelland, Weiping Zhou, A. James O’Malley, and Nancy E. Morden, “State Legal Restrictions and Prescription-Opioid Use among Disabled Adults,” New England Journal of Medicine, 375, 2016, 44-53.

Miech, Richard A., Lloyd D. Johnson, Patrick M. O’Malley, et al., (2019). “Monitoring the Future national survey results on drug use, 1975-2018: Volume I, Secondary school students.”, Ann Arbor: Institute for Social Research, The University of Michigan, 2019, available at http://monitoringthefuture.org/pubs.html\#monographsIns.

Miniño, A. M., Anderson, R. N., Fingerhut, L. A., Boudreault, M. A., \& Warner, M. (2006). Deaths: injuries, 2002. National vital statistics reports. vol. 54. No. 10. Hyattsville, MD: National Center for Health Statistics.

Nahin, Richard L., Bryan Sayer, Barbara J. Stussman, Termeh M. Feinberg, "Eighteen-Year Trends in the Prevalence of, and Health Care Use for, Noncancer Pain in the United States: Data from the Medical Expenditure Panel Survey,” The Journal of Pain, 2019, 20(7): 796809.

National Academies of Sciences, Engineering, and Medicine. High and Rising Mortality Rates Among Working-Age Adults. Washington, DC: The National Academies Press, 2021.

National Drug Intelligence Center, Oxycontin Diversion and Abuse, January 2001.

Nutt, David, Leslie King, William Saulsbury, and Colin Blakemore, "Development of a rational scale to assess the harm of drugs of potential misuse," Lancet. 2007; 369: 1047-1053. 
Office of the Inspector General, Department of Justice, "Review of the Drug Enforcement Administration's Regulatory and Enforcement Efforts to Control the Diversion of Opioids,” Washington, D.C.: Department of Justice, Evaluation and Inspection Division 19-05, 2019.

Ohler, Norman, Blitzed: Drugs in the Third Reich, New York: Houghton Mifflin Harcourt, 2017.

Pardo, Bryce, Jerka, Jonathan P. Caulkins, and Peter Reuter, The future of fentanyl and other synthetic opioids. RAND Corporation, 2019.

Pathan, Hasan, and John Williams. "Basic opioid pharmacology: an update.” British journal of pain vol. 6,1 (2012): 11-6.

Pierce, Justin R., and Peter K. Schott, "Trade liberalization and mortality: evidence from US counties.” American Economic Review: Insights, 2020, 2(1), 47-64.

Podolsky, Scott H., David Herzberg, and Jeremy A. Greene, "Preying on Prescribers (and Their Patients): Pharmaceutical Marketing, Iatrogenic Epidemics, and the Sackler Legacy,” New England Journal of Medicine, 2019, 380:1785-1787.

Porter Jane, and Hershel Jick, “Addiction rare in patients treated with narcotics,” New England Journal of Medicine, 1980; 302:123-123.

Purdue Pharma, “I Got My Life Back,” https://www.youtube.com/watch?v=Er78Dj5hyeI, 1998.

Quinones, Samuel, Dreamland, New York: Bloomsbury Press, 2015.

Ruhm, C. J. (2018). Corrected US opioid-involved drug poisoning deaths and mortality rates, 1999-2015. Addiction, 113(7), 1339-1344.

Ruhm, C. J. (2019). Drivers of the fatal drug epidemic. Journal of health economics, 64, 25-42.

Sarpatwari, Ameet, Michael S. Sinha, and Aaron S. Kesselheim, “The Opioid Epidemic: Fixing a Broken Pharmaceutical Market,” Harvard Law and Policy Review, 11(2), 2017, 463-484. 
Saunders, Nicholas J., The Poppy: A History of Conflict, Loss, Remembrance, and Redemption, United Kingdom: Oneworld Publications, 2014.

Tough, Paul, “The Alchemy of Oxycontin,” New York Times Magazine, July 29, 2001.

United Nations Office on Drugs and Crime, A Century of International Drug Control, October 2010.

United States House of Representatives, Committee on Energy and Commerce, Subcommittee on Oversight and Investigations, “OxyContin: Its Use and Abuse,” Serial Number 107-54, Washington, D.C.: Government Printing Office, August 28, 2001.

Van Zee, Art. "The promotion and marketing of oxycontin: commercial triumph, public health tragedy.” American journal of public health, 2009, 99(2): 221-227.

Zhu, Wenjai, Michael E. Chernew, Tisamarie B. Sherry, and Nicole Maestas, "Initial opioid prescriptions among U.S. commercially insured patients, 2012-2017.” New England Journal of Medicine, 2019; 380:1043-52. 
Figure 1: Trends in age- and sex-adjusted drug deaths and opioid deaths, 1990-2018

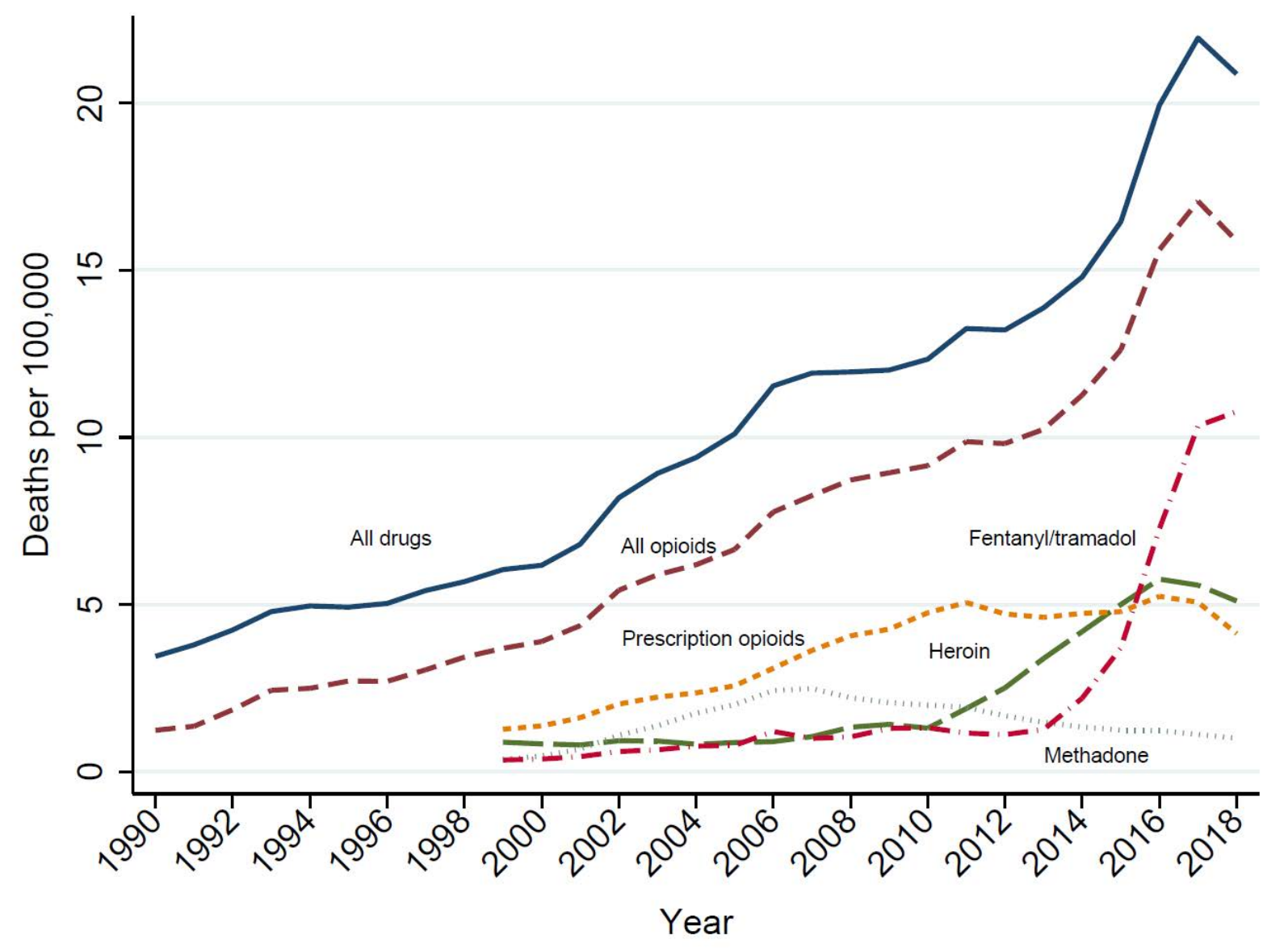

Notes: Data are from the Centers for Disease Control and Prevention, National Vital Statistics System. Drug deaths after 1999 were identified based on International Classification of Diseases, $10^{\text {th }}$ edition underlying cause-of-death codes X40-X44, X60-X64, X85, and Y10-Y14. Overdoses by category were identified by multiple-cause-of-death codes T40.1 (heroin), T40.2 (prescription opioids = natural and semisynthetic opioids), T40.3 (methadone), and T40.4 (fentanyl/tramadol = synthetic opioids other than methadone) (Hedegaard, Miniño, and Warner, 2018). Total opioid deaths also included code T40.6 (other/unspecified narcotics). Drug deaths before 1999 were identified based on International Classification of Diseases, $9^{\text {th }}$ edition underlying cause-of-death codes E850-E858, E950.0-E950.5, E9620, and E980.0-E980.5. Opioid deaths before 1999 were identified from underlying cause-of-death-codes E850.1-E850.2 and 305.5, as well as multiple-cause-of-death codes 965.00-965.09 (Fingerhut \& Cox (1998). Deaths involving more than one opioid category are counted in both. To account for the change from ICD-9 codes (1990-1998) to ICD-10 codes (1999-2017), the following comparability ratios were applied to ICD-9 codes E850-E858, E950-E950.5, E9620, and E980.0-E980.5 (respectively) in the calculation of total drug deaths: 1.0365, 1.0013, 0.9870, and 1.0417 (Miniño, et al., 2002). Total opioid deaths were adjusted upward by about 20 percent (comparability ratio $=1.195$ ) (Hoyert, et al., 2001). Deaths were age- and sex- adjusted to the US 2000 population. Deaths from specific causes were adjusted for underreporting following Ruhm (2018), as described in the Online Appendix. 
Figure 2: Trends in Opioid Shipments per Adult, 1997-2017

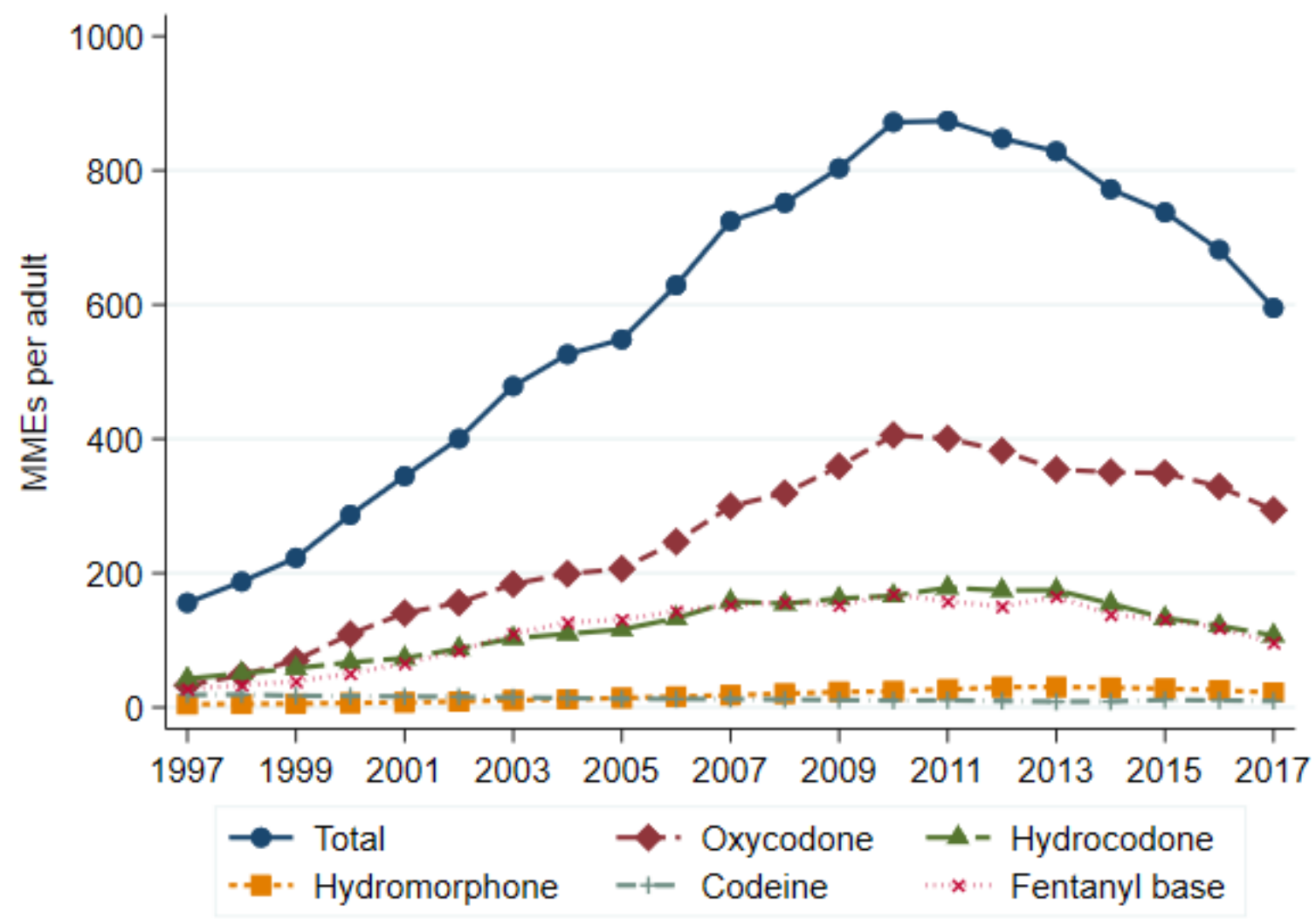

Note: The figure shows milligrams of morphine equivalents per adult in the US from 1997 to 2017. Data are from the DEA ARCOS database. The total omits methadone and buprenorphine, which are often used in treating opioid abuse, along with some smaller opioids for which data are not available in all years. Data for hydromorphone, codeine, morphine, and fentanyl base was missing in 2000 and was imputed using data in 1999 and 2001, assuming a constant growth rate. The same was done for total shipments. 
Figure 3: Trends in Pain, Mental Health, Despair, and Social Isolation

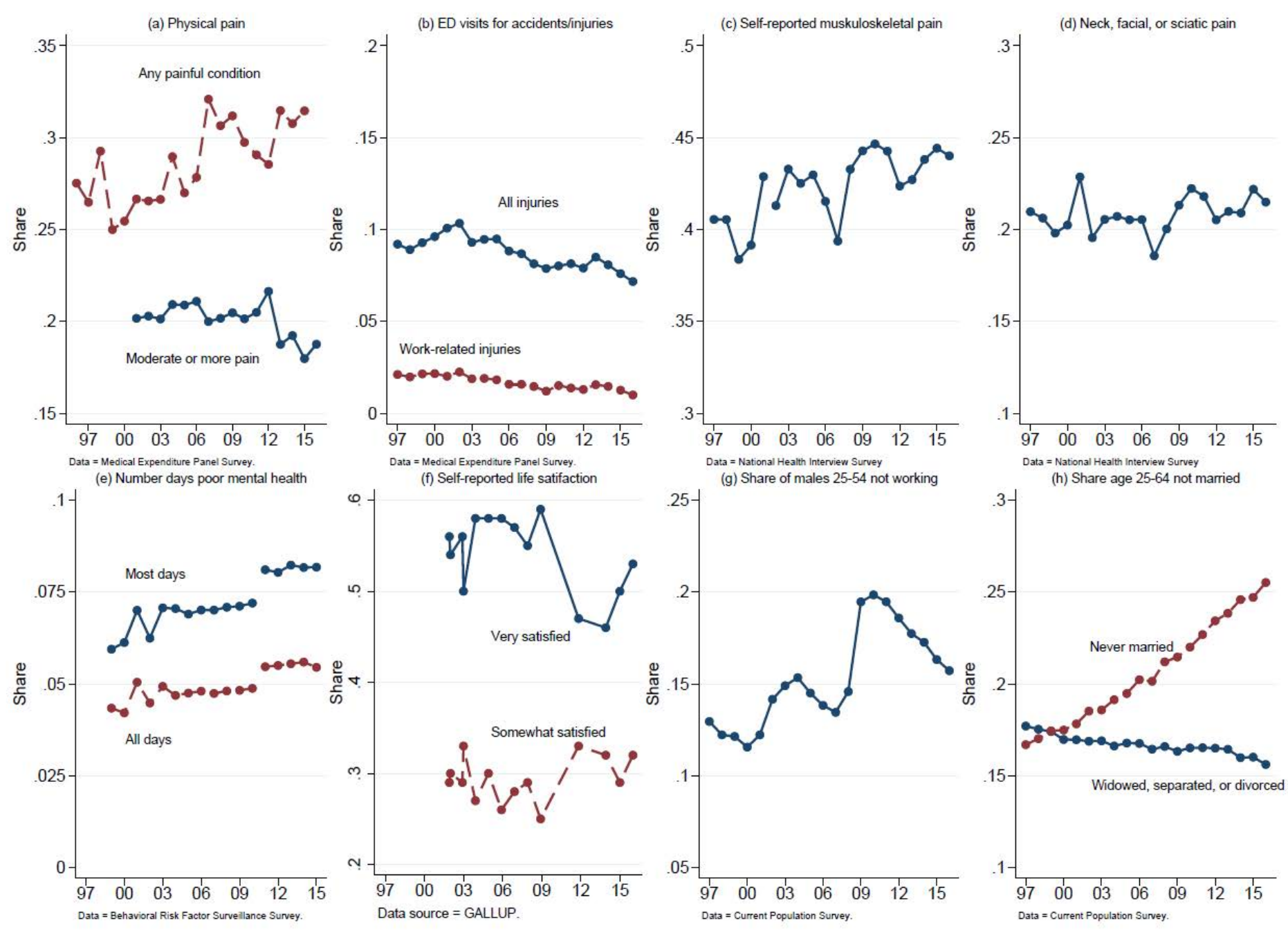


Figure 4: Pain and the Initiation of Opioids

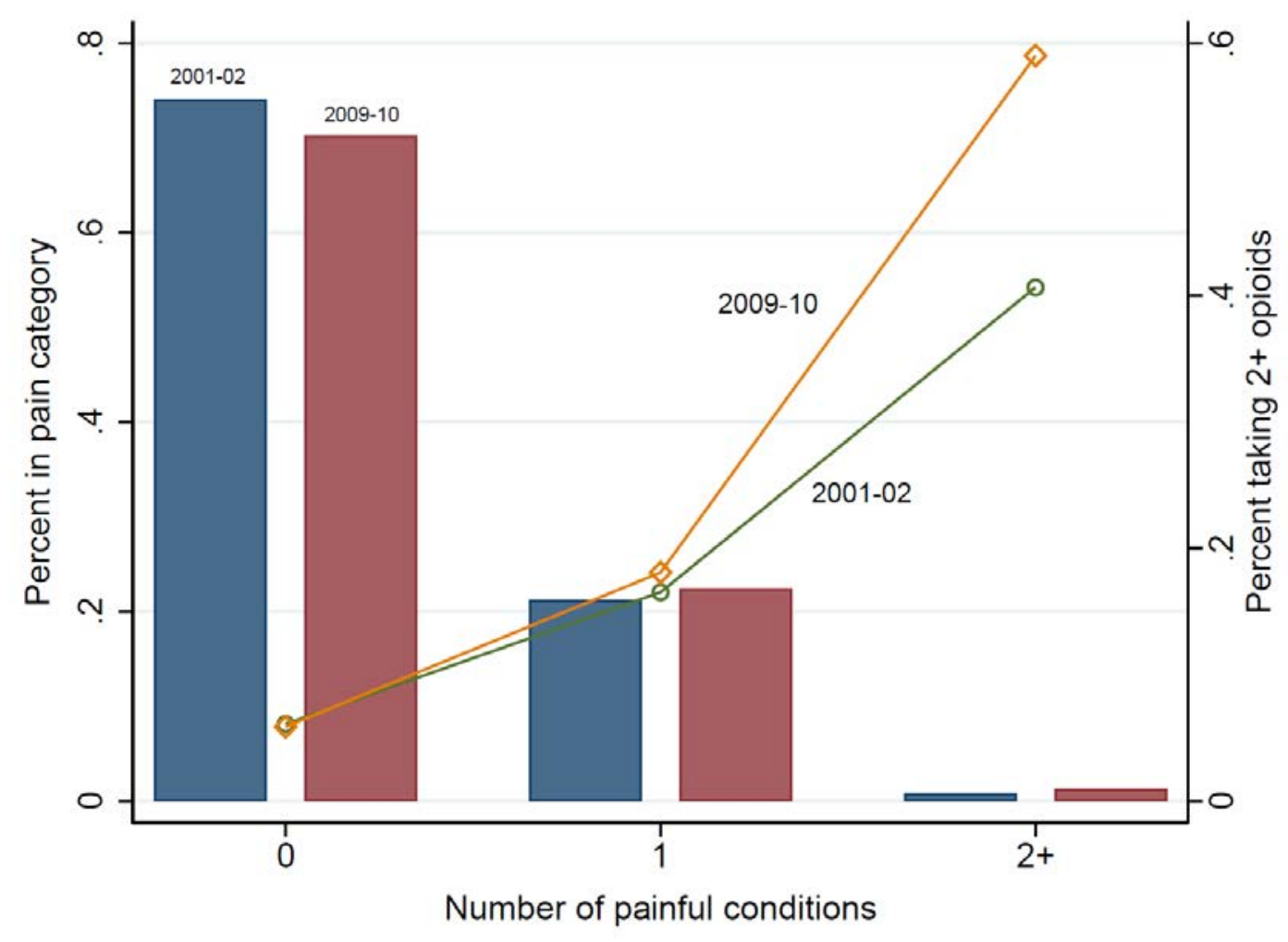

Note: Data are from the Medical Expenditure Panel Study. Painful conditions include sickle cell anemia, headache (including migraine), nonspecific chest pain, rheumatoid arthritis and related disease, osteoarthritis, other nontraumatic joint disorders, spondylosis (including intervertebral disc disorders, other back problems), joint disorders and dislocations (trauma-related), all fractures, sprains and strains, and abdominal pain. 
Figure 5: Age-adjusted opioid deaths (per 100,000) by commuting zone.
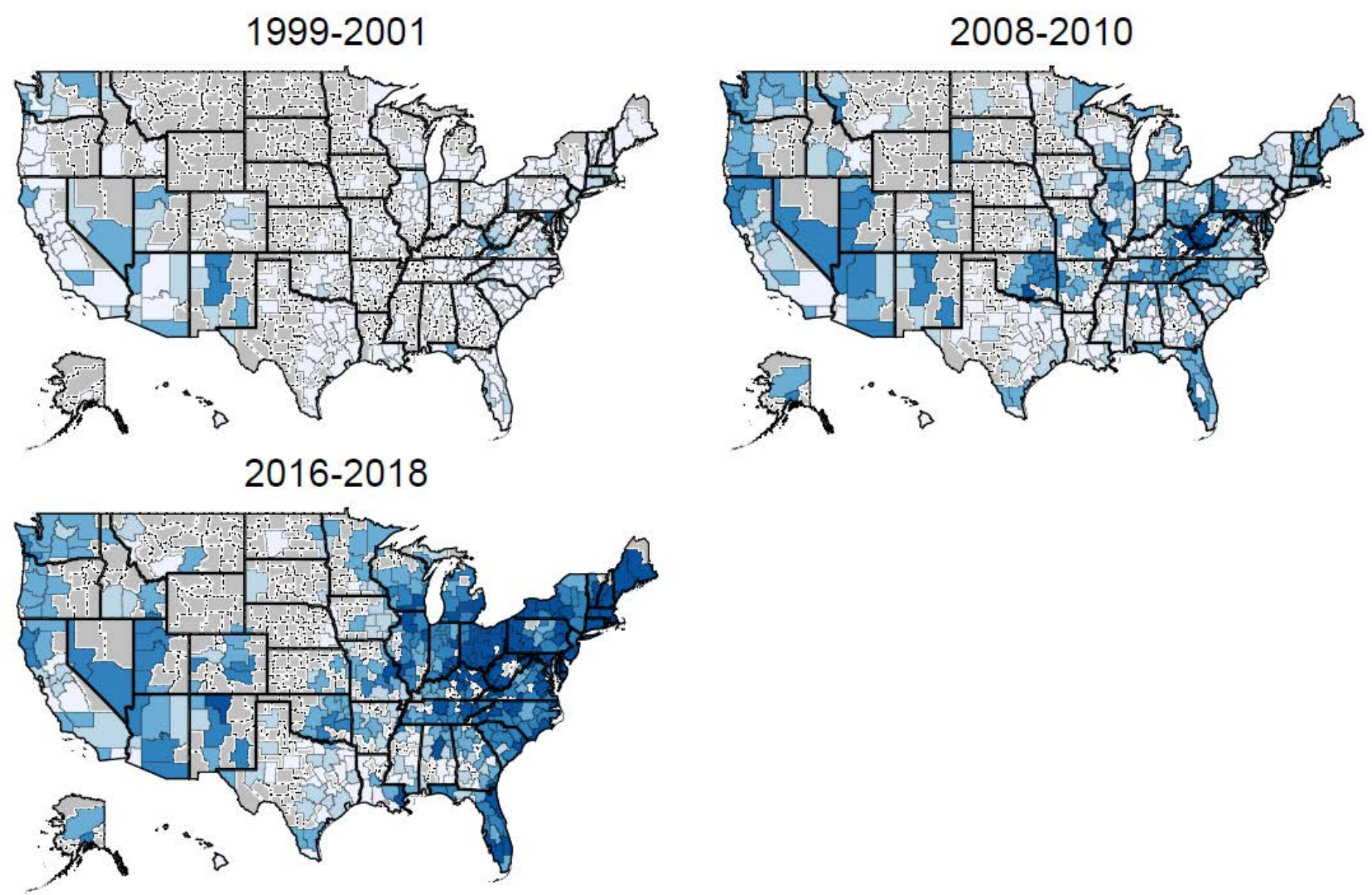

Annual Opioid Deaths per 100,000
$19-82$
$11-19$
$\square 6-11$
$\square 4-6$
$1-4$
No data

Note: Data are from the Center for Disease Control and Prevention, National Vital Statistics System. Due to CDC restrictions, areas are not shown if the number of deaths $<10$ in the three-year total or the commuting zone population is $<100,000$ people. These areas are indicated with grey fill and white boundaries. Data are adjusted to the year 2000 population by age and sex. 


\begin{tabular}{|c|c|c|c|c|c|c|c|}
\hline & \multicolumn{5}{|c|}{ Prescription Opioid Shipments (1997-2010) } & \multirow{2}{*}{$\begin{array}{c}\begin{array}{c}\text { Prescription Opioid } \\
\text { Death Rate (1997- } \\
\text { 2010) }\end{array} \\
(6) \\
\end{array}$} & \multirow{2}{*}{$\begin{array}{c}\begin{array}{c}\text { Illicit Opioid } \\
\text { Death Rate } \\
\text { (2008-2017) }\end{array} \\
(7) \\
\end{array}$} \\
\hline & (1) & $(2)$ & (3) & $(4)$ & (5) & & \\
\hline \multicolumn{8}{|l|}{$\begin{array}{l}\text { Interaction between national opioid } \\
\text { shipments/illegal deaths and } \\
\text { Pain }\end{array}$} \\
\hline \% of labor force claiming DI (1990) & $\begin{array}{l}86.10^{* * *} \\
(10.73)\end{array}$ & & & & $\begin{array}{c}55.90 \\
(41.86)\end{array}$ & $\begin{array}{l}1.11^{*} \\
(0.60)\end{array}$ & $\begin{array}{l}3.02^{*} \\
(1.57)\end{array}$ \\
\hline Self-reported joint pain prevalence & & $\begin{array}{l}65.83^{* *} \\
(31.26)\end{array}$ & & & $\begin{array}{c}38.83 \\
(32.22)\end{array}$ & $\begin{array}{l}0.61^{* *} \\
(0.28)\end{array}$ & $\begin{array}{l}3.01^{* * *} \\
(1.00)\end{array}$ \\
\hline \multicolumn{8}{|l|}{ Despair } \\
\hline Share dissatisfied/very dissatisfied w/ life & & & $\begin{array}{c}33.98 \\
(28.26)\end{array}$ & & $\begin{array}{l}-70.94^{* *} \\
(29.63)\end{array}$ & $\begin{array}{l}-0.49 \\
(0.33)\end{array}$ & $\begin{array}{c}1.32 \\
(1.08)\end{array}$ \\
\hline $\begin{array}{l}\text { Extreme mental distress (30 days w/ poor } \\
\text { mental health) }\end{array}$ & & & & $\begin{array}{l}140.86^{* * *} \\
(28.27)\end{array}$ & $\begin{array}{c}149.03^{* * *} \\
(36.38)\end{array}$ & $\begin{array}{l}1.27^{* * *} \\
(0.38)\end{array}$ & $\begin{array}{l}-0.09 \\
(1.04)\end{array}$ \\
\hline $\begin{array}{l}\text { Opioid shipments } \\
\text { Oxycodone MME per capita, 1997-2010 }\end{array}$ & & & & & & & $\begin{array}{c}4.47^{* * *} \\
(1.11)\end{array}$ \\
\hline Unadjusted mean & 368.575 & 373.675 & 373.675 & 373.675 & 373.675 & 3.533 & 8.865 \\
\hline $\mathrm{R}^{2}$ & 0.750 & 0.713 & 0.707 & 0.738 & 0.747 & 0.448 & 0.607 \\
\hline $\mathrm{N}$ & 42,966 & 4,634 & 4,634 & 4,634 & 4,634 & 3,968 & 3,641 \\
\hline
\end{tabular}

The dependent variable is age- and sex-adjusted rate in the county and year. Column (1) includes all counties. Columns (2)-(7) only include counties for which data on joint pain prevalence or share dissatisfied with life were available. National opioid shipments included shipments of oxycodone, hydrocodone, hydromorphone, codeine, morphine, and fentanyl base and were scaled by the change in shipments between 1997 and 2010 in Figure 2 . The coefficients represent the impact of one standard deviation higher pain (or despair) times the change in national opioid shipments or national deaths due to illegal opioids which occurred over the period. Counties were weighted by total population in 2005. All regressions control for county and year fixed effects. Standard errors are clustered at the county-level and are reported in parentheses. $* * *(* *) *$ denote $\mathrm{p}<0.01(\mathrm{p}<0.05) \mathrm{p}<0.10$. 